\title{
Rapid Diagnosis of Sonne Dysentery by Means of Immunofluorescence
}

\author{
C. E. D. TAYLOR,* M.A., M.D., M.C.PATH., DIP.BACT., F.R.S.H. ; G. V. HEIMER, † F.I.M.L.T.
}

Brit. med. F., 1964, 2, 165-166

Taylor, Heimer, Lea, and Tomlinson (1964) compared a fluorescent antibody technique with a cultural method for the detection of Shigella sonnei in faeces, and found that the two methods agreed in $72.3 \%$ of the 394 specimens examined; 57 $(14.5 \%)$ specimens were positive by culture only; and 52 (13.2\%) were positive by immunofluorescence but not by culture. Most of the latter were thought to be "false-positive" results, which were investigated in considerable detail, but the cause was not found (Taylor et al., 1964). Nevertheless it was clear that when only few fluorescing organisms were seen in a specimen it was more often negative by culture than when large numbers of fluorescing organisms were observed. It was emphasized that the benefit of fluorescence microscopy lies in the speed with which a presumptive positive result can be obtained. Taylor et al. (1964) concluded that the method could be employed with advantage in outbreaks of diarrhoea but that the technique was not reliable enough in their hands at that time for the examination of specimens from sporadic cases of diarrhoea, from contacts of cases of Sonne dysentery, or from persons convalescent from Sonne dysentery.

We report here the results of a subsequent investigation on specimens submitted from cases of acute diarrhoea, mostly by general practitioners, to four public health laboratories in North London.

\section{Materials and Methods}

The two fluorescent conjugates used in this study were from the same batch as those described by Taylor et al. (1964). One was prepared from antiserum against a phase 1 (N.C.T.C. No. 9773) and the other from antiserum against a phase 2 (N.C.T.C. No. 8219) strain of Sh. sonnei by conjugation with fluorescein isothiocyanate.

Microscopical preparations were made on 3 by 1 -in. ( 7.5 by $2.5-\mathrm{cm}$.) microscope slides 0.8 to $1 \mathrm{~mm}$. in thickness. A smear of faeces covering an area of approximately 1 by $\frac{1}{2}$-in. $(2.5$ by $1.3-\mathrm{cm}$.) was made in the centre of the slide. After leaving the smear on the bench to dry, it was gently fixed by heat from a Bunsen flame. A mixture of Sh. sonnei phase 1 and 2 conjugates, diluted to their highest effective dilution $(1 / 20)$ in Bacto F.T.A. phosphate buffer $p H$ 7.2, was spread over the smear and allowed to react for 15 minutes at room temperature. The slide was then washed in gently running tap-water, finally rinsed in phosphate buffer, and allowed to dry in a sloping position on blotting-paper.

This method of making the microscopical preparations differs from that described by Taylor et al. (1964) in the following respects: (a) a separate slide was used for each specimen instead of making four smears on each slide; $(b)$ smears were fixed by heat instead of methanol; (c) the mixture of Sh. sonnei phase 1 and 2 conjugates was allowed to react on the slide for 15 minutes at room temperature instead of for 20 minutes at $37^{\circ} \mathrm{C}$. in a Petri dish containing moistened filter-paper ; (d) smears were washed in gently running tap-water instead of three changes of phosphate-buffered saline; $(e)$ the phosphate buffer used for diluting the conjugates and for the final wash

\footnotetext{
* Consultant Bacteriologist, Diagnostic Reference Laboratory, Central Public Health Laboratory, Colindale, London.

† Chief Technician, Diagnostic Reference Laboratory, Central Public Health Laboratory, Colindale, London.
}

had a $p H$ of 7.2 instead of $8 ;(f)$ microscopical preparations were examined unmounted instead of mounting in Elvanol and covering with a No. 1 glass coverslip.

Preparations were examined in a darkened cabinet by means of a Watson Bactil microscope fitted with a dark-ground condenser. Carl Zeiss fluorescence-free immersion oil ${ }^{1}$ was used. The light source was a 250 -watt ME/D mercury-vapour compact source lamp. ${ }^{2}$ The excitation filter was an OX1 2-mm.-thick Chance-Pilkington glass filter. Within the body of the microscope was placed an $805 \mathrm{Q}$ Ilford colourless gelatin ultra-violet barrier filter. During microscopical examination special attention was paid to the edge of each smear, where experience had shown that fluorescent organisms are most readily observed. Smears in which fluorescent organisms were few or weakly fluorescing were regarded as negative, for experience had taught that, when such preparations were regarded as positive, results of microscopy were rarely confirmed by culture.

Results of fluorescence microscopy were recorded before results of culture were known.

In all four laboratories specimens were cultured on deoxycholate citrate agar similar to that described by Taylor et al. (1964).

\section{Results}

The Table shows that of a total of 388 specimens examined $68(17.5 \%)$ were positive by fluorescence microscopy as well as by culture ; $303(78.1 \%)$ were negative by both methods; $7(1.8 \%)$ were positive by fluorescence microscopy but negative by culture; and $10(2.6 \%)$ were negative by fluorescence microscopy but positive by culture.

Results of a Fluorescent Antibody Technique Compared With Those of a Cultural Method for the Detection of Sh. sonnei in Faecal Spectmens from Patients with Acute Diarrhoea.

\begin{tabular}{|c|c|c|c|c|c|c|c|c|c|c|}
\hline \multirow{2}{*}{ 官 } & \multirow[t]{2}{*}{ Laboratory } & \multicolumn{2}{|c|}{$\begin{array}{l}\text { Fluor. + } \\
\text { Cult. + }\end{array}$} & \multicolumn{2}{|c|}{$\begin{array}{l}\text { Fluor. - } \\
\text { Cult. - }\end{array}$} & \multicolumn{2}{|c|}{$\begin{array}{l}\text { Fluor. + } \\
\text { Cult. - }\end{array}$} & \multicolumn{2}{|c|}{$\begin{array}{l}\text { Fluor. - } \\
\text { Cult. + }\end{array}$} & \multirow{2}{*}{ Total } \\
\hline & & No. & $\%$ & No. & $\%$ & No. & $\%$ & No. & $\%$ & \\
\hline \multirow[t]{2}{*}{$\begin{array}{l}\mathbf{A} \\
\mathbf{B}\end{array}$} & $\begin{array}{l}\text { Colindale } \\
\text { Coppetts Wood; }\end{array}$ & & $16 \cdot 3$ & 260 & & 4 & $1 \cdot 2$ & 8 & $2 \cdot 5$ & 325 \\
\hline & $\begin{array}{l}\text { Edmonton; } \\
\text { Neasden }\end{array}$ & 15 & $23 \cdot 8$ & 43 & $68 \cdot 2$ & 3 & $4 \cdot 8$ & 2 & $3 \cdot 2$ & 63 \\
\hline \multicolumn{2}{|c|}{ All 4 laboratories } & 68 & $17 \cdot 5$ & 303 & $78 \cdot 1$ & 7 & 1.8 & 10 & $2 \cdot 6$ & 388 \\
\hline
\end{tabular}

The amount of disagreement between groups A and B is not statistically significant at the $5 \%$ level.

These results show $95.6 \%$ agreement between the fluorescent antibody technique and the cultural method; $1.8 \%$ of the results may be regarded as "false positive" by the fluorescence technique and $2.6 \%$ as "false negative."

\section{Discussion}

In the light of this study we consider that the conclusion of Taylor et al. (1964) that the fluorescent antibody technique

\footnotetext{
${ }^{2}$ Obtained from Degenhardt and Co. Ltd., 20-22 Mortimer Street, London $W .1$

2 Obtained from Cooke Troughton and Simms Ltd., Broadway Court, Westminster, London S.W.1.
} 
was not reliable enough for the diagnosis of sporadic cases of acute Sonne dysentery should be revised. Our confidence in the immunofluorescence technique described in this paper is such that it is our current practice to examine specimens from cases of acute diarrhoea immediately on arrival in the laboratory and to inform the doctor by telephone as soon as a positive result by fluorescence microscopy is obtained, emphasizing that such a report should be regarded as provisional and subject to confirmation by culture. With the fluorescent antibody technique in the manner here described, a provisional diagnosis can be made with reasonable confidence in cases of acute Sonne dysentery within one hour of the faecal specimen arriving in the laboratory.

The very much better agreement in this study between immunofluorescence and culture, as compared with that of Taylor et al. (1964), is probably related to the way in which the microscopical preparations were examined and evaluated, although changes in the technique of making the microscopical preparations, which were introduced mainly for reasons of convenience, could have contributed to the overall improvement. Searching for fluorescing organisms along the edges of smears may have reduced the number of false-negative results, and disregarding fluorescent particles other than those having the typical morphology of fluorescing $S h$. sonnei probably reduced the number of false-positive ones. There is little doubt that in the earlier study many of the false-positive results were caused by attaching significance to fluorescing particles not having the typical morphology of fluorescing Sh. sonnei, because at that time it was thought that morphologically atypical forms might well occur in faeces. Our experience has shown, however, that in microscopical preparations of faecal specimens from cases of acute Sonne dysentery fluorescing organisms of typical morphology are usually seen in large numbers.

\section{Summary}

A fluorescent antibody technique for the detection of $S h$. sonnei in specimens of faeces from cases of acute diarrhoea is described. It has been compared with a cultural method. The two procedures agreed in $95.6 \%$ of 388 specimens examined; $7(1.8 \%)$ of the results are regarded as "false positive" by the fluorescence technique and $10(2.6 \%)$ are regarded as "false negative." The technique enables a provisional report to be telephoned within one hour of a specimen arriving in the laboratory, and is regarded as a useful procedure for the rapid diagnosis of Sonne dysentery, provided it is combined with a cultural method.

We are grateful to Dr. R. C. J. James, Director of the Public Health Laboratory at Neasden Hospital; to Dr. K. Machacek, Director of the Public Health Laboratory at Coppetts Wood Hospital ; and to Dr. M. E. M. Thomas, Director of the Public Health Laboratory at Edmonton, for sending us fresh specimens of faeces and allowing us to use their results of culture. The antisera used for preparing the fluorescent conjugates were kindly supplied by Dr. C. M. P. Bradstreet, Director of the Standards Laboratory for Serological Reagents, Colindale.

\section{REFERENCE}

Taylor, C. E. D., Heimer, G. V., Lea, D. J., and Tomlinson, A. J. H. (1964). अ. clin. Path., 17, 225.

\title{
Congenital Rubella Infection of a Human Embryo
}

\author{
H. E. M. KAY,* M.D., M.R.C.P. ; MARGARET E. PEPPERCORN, M.B., B.CH. ; J. S. PORTERFIELD,† M.D., M.R.C.S. \\ K. MCCARTHY, $\ddagger$ M.D. ; C. H. TAYLOR-ROBINSON,§ M.B., B.S.
}

Brit. med. F., 1964, 2, 166-167

The association between maternal infection with rubella (German measles) and the subsequent birth of a deformed child was first noted by Gregg (1941) and has been amply confirmed by later reports. Little progress could be made on studying the mechanism whereby these congenital defects were produced until satisfactory means were found for cultivating the virus in the laboratory (Weller and Neva, 1962 ; Parkman et al., 1962 ; McCarthy et al., 1963).

During the spring and summer of 1962 a number of human embryos from pregnancies which were terminated after maternal exposure to rubella became available for study. Attempts were made to demonstrate the presence of virus in cultures prepared from this material. This paper describes the isolation of rubella virus from one of these embryos.

\section{Materials and Methods}

Embryo 13 was removed by hysterotomy performed $23 \frac{1}{2}$ weeks after the last menstrual period on a mother who gave

* Consultant Clinical Pathologist, Royal Marsden Hospital, London.

† Member of Scientific Staff, National Institute for Medical Research, Mill Hill, London.

‡ Senior Lecturer, Department of Bacteriology, University of Liverpool.

$\S$ Research Fellow, Department of Bacteriology, University of Liverpool. a history of an attack of rubella during the fifth week of pregnancy. Lung tissue was minced and trypsinized overnight at $4^{\circ} \mathrm{C}$., and cultures were set up in Gey's solution containing lactalbumin hydrolysate and newborn calf serum (Porterfield, 1962). Subcultivation of cells was carried out, using essentially the method of Hayflick and Moorhead (1961). Cells homogenized in medium were frozen at $-70^{\circ}$ C. for later examination.

\section{Results}

Homogenates of third-passage-level human embryonic lung cells were used to infect cultures of rabbit-kidney cells of the strain GL RK13. These produced a cytopathic effect visible by direct and phase contrast microscopy, which was reproduced by the third to the fifth day in seven serial cultivations in rabbit cells. Control cultures subcultured at the same time remained negative.

Neutralization tests were carried out, using serum from a rabbit immunized by five intravenous injections of GL RK13 grown rubella virus (strain "Judith") which had been isolated in Liverpool. The seventh GL RK13 pass of HEL $13 / 3$ virus was neutralized by this serum at a dilution of $1: 32$, and a similar dose of "Judith" virus was neutralized by 